\title{
Primary pure lymphoepithelioma-like carcinoma of the ureter
}

\author{
J. Fernando Val-Bernal ${ }^{1}$
}

Received: 20 June 2017 / Accepted: 28 June 2017 /Published online: 11 July 2017

(C) Springer-Verlag GmbH Deutschland 2017

\section{Dear Sir,}

I read with great interest the recent paper by Lopez-Beltran and co-authors (DOI 10.1007/s00428-017-2117-z) on lymphoepithelioma-like carcinoma of the upper urinary tract [1]. In the review of the literature, these authors include 14 cases of this uncommon condition (their Table 4). However, our work on this tumor is missing. Thus, in 2011, we described one case of this neoplasm [2]. A 62year-old woman underwent a right radical nephrectomy for conventional renal cell carcinoma in 1995. The tumor was Fuhrman grade 1, pT1, N0, M0 (stage I AJCC). During the next 14 years, the patient was periodically checked in the urology service. She remained well until 2009 when she consulted because of recurrent urinary tract infections. An ultrasound scan showed an upper pole hydronephrosis in a complete duplicate collecting system. Repeated urine examinations detected malignant epithelial cells in the smears. A computed tomographic scan of the abdomen and pelvis revealed the presence of a $2 \times 0.8 \mathrm{~cm}$ lesion involving the wall of the left midureter with ureteral dilatation and upper pyelocaliceal system hydronephrosis. The patient underwent a left partial nephrectomy of the upper pole, ureterectomy, and left-sided pelvic lymphadenectomy in 2010 when she was 76 years old.

Microscopic study of the ureteral lesion revealed a pure lymphoepithelioma-like carcinoma of the ureter. The inflammatory lymphoid infiltrate was so dense as to obscure

J. Fernando Val-Bernal apavbj@humv.es

1 Pathology Unit, Medical and Surgical Sciences Department, University of Cantabria and IDIVAL, Santander, Spain the epithelial component of the tumor, thus raising the diagnostic concern for a lymphoma. Some eosinophils were present. The tumor consisted of large undifferentiated cells with large pleomorphic nuclei and prominent nucleoli in a syncytial arrangement. Immunohistochemistry revealed diffuse, strong reactivity for cytokeratins (AE1/AE3, 18, and 7) and p53 for undifferentiated cells. The lymphoid background was positive for CD3 and CD20 with a slight predominance of $\mathrm{CD} 3+$ cells. The neoplastic cells were negative for Epstein-Barr virus by immunohistochemistry. The tumor infiltrated the deep muscular layer. Surgical margins were negative.

Lymphadenectomy comprised a $3 \times 3 \times 2 \mathrm{~cm}$ fragment of adipose tissue, not including lymph nodes.

The patient did not receive subsequent radiotherapy. After 5 months, she was alive, asymptomatic, and free of tumor.

The authors did not take into account our study with a comparable title. We would like our report to receive appropriate recognition.

\section{Compliance with ethical standards}

Conflict of interest The author declares no conflict of interest.

Funding There is no external funding for this work.

\section{References}

1. Lopez-Beltran A, Paner G, Blanca A, Montironi R, Tsuzuki T, Nagashima Y, Chuang S-S, Win KT, Madruga L, Raspollini MR, Cheng L (2017) Lymphoepithelioma-like carcinoma of the upper urinary tract. Virchows Arch 470:703-709

2. Val-Bernal JF, González-Márquez P, Ballestero R, Zubillaga S (2011) Primary lymphoepithelioma-like carcinoma of the ureter. Ann Diagn Pathol 15:218-220 